\title{
Symmetric Lipomatosis of the Tongue: Report of a Case
}

\author{
Yoshinori Jinbu ${ }^{1}$, Kaoru Otawa ${ }^{1}$, Yuri Obi ${ }^{1}$, Taku Tsukahara ${ }^{1}$, Mikio Kusama ${ }^{1}$ and Hidemi Nakagawa $^{2}$ \\ ${ }^{1}$ Department of Dentistry, Oral and Maxillofacial Surgery, ${ }^{2}$ Department of Dermatology, Jichi Medical School, Tochigi, Japan
}

\begin{abstract}
Jinbu Y, Otawa K, Obi Y, Tsukahara T, Kusama M and Nakagawa H. Symmetric lipomatosis of the tongue: Report of a case. Oral Med Pathol 2004 ; 9: 123-126, ISSN 1342-0984.

A case of symmetric lipomatosis of the tongue is reported. The patient was a 72-year-old Japanese male who complained of a bilateral swelling of the tongue. The tongue of the patient was diffusely and markedly enlarged with somewhat nodular appearance in the lateral borders, presenting as a macroglossia.

Histopathologically, the biopsy specimen showed adipose tissues which consisted of mature lipocytes. Partial glossectomy was performed. Adipose tissues were interspersed with the muscles fibers and distinct capsule formation was not found. The patient was finally diagnosed as having symmetric lipomatosis of the tongue based on the clinical, radiological and histopathological findings.
\end{abstract}

Key words: symmetric lipomatosis of the tongue, benign symmetric lipomatosis, macroglossia Correspondence: Yoshinori Jinbu, Department of Dentistry, Oral and Maxillofacial Surgery,

Jichi Medical School, Yakushiji 3311-1, Minamikawachi-machi, Kawachi-gun, Tochigi, 329-0498, Japan

Phone: +81-286-58-7390, Fax: +81-285-44-8669

\section{Introduction}

Lipoma is one of the non-epithelial benign tumors occasionally seen in the oral cavity. However, symmetric lipomatosis, a subtype of lipomas, is an extremely rare disease in the oral cavity, and only 6 cases of symmetric lipomatosis of the tongue (SLT) have been reported in the literature (1-5).

This case report describes a patient who presented with a bilateral lingual swelling and who was finally diagnosed as having SLT.

\section{Case Report}

A 72-year-old Japanese male was referred to the Department of Dentistry, Oral and Maxillofacial Surgery, Jichi Medical School Hospital by his physician on December 27, 2002, with a complaint of tongue swelling. The patient first noticed the tongue swelling 2 years before. He was unaware of pain or difficulty in swallowing, but the swelling had gradually increased.

The patient was a mild diabetic, and his diabetes mellitus was well controlled by diet. He had no other remarkable medical history. Physical status was as follows: height $165 \mathrm{~cm}$; body weight $55.15 \mathrm{~kg}$; body temperature $36.6{ }^{\circ} \mathrm{C}$; pulse $66 / \mathrm{min}$; blood pressure $132 / 74$; and respiration $16 / \mathrm{min}$. The tongue of the patient was diffusely and markedly enlarged with a somewhat nodular appearance in the lateral borders, presenting as a macroglossia (Fig. 1). The surface of mucosa showed normal color with no erosions or ulcers. The lateral border of the tongue showed elastic soft to palpation and the lesion was unaccompanied by pain. There were no abnormal values in the general blood examination.

A biopsy was performed with a clinical diagnosis of amyloidosis of the tongue. After incision in the lateral border of the tongue, yellowish adipose tissues were seen just beneath the epithelium (Fig. 2). Histopathologically, the specimen showed adipose tissue consisting of mature lipocytes, and the histopathological diagnosis was lipoma (Fig. 3).

MR image showed diffuse and irregular high intensity areas in the lateral border of the tongue in the T1 weighted image (Fig. 4).

Although there was no interference with functions of the tongue and mouth, partial glossectomy was carried out under general anesthesia to reduce the volume of the tongue. Incision was made in the bilateral border and a proper amount of adipose tissue was removed. Adipose tissues were interspersed with the muscles fibers, and distinct capsule formation was not found (Figs. 5, 6). The wound healing process was normal.

The patient was finally diagnosed as having symmetric lipomatosis of the tongue based on the clinical, 


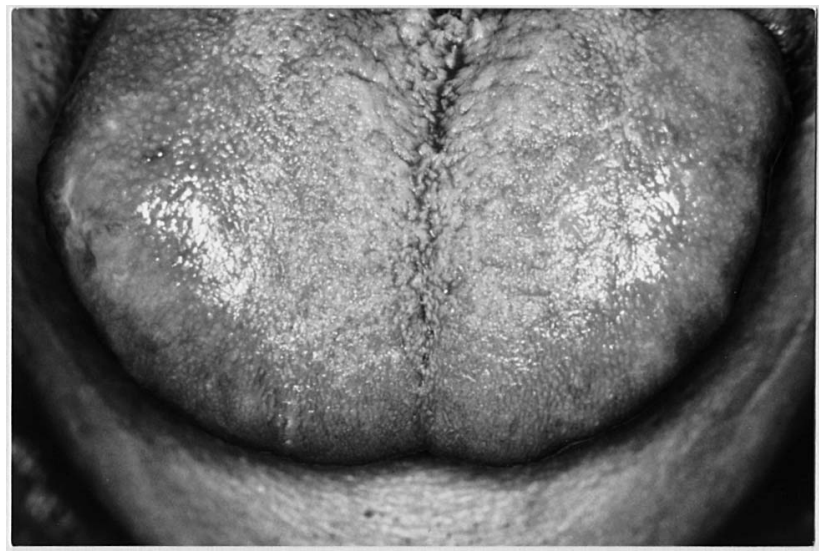

Fig. 1: The tongue was diffusely and markedly enlarged.

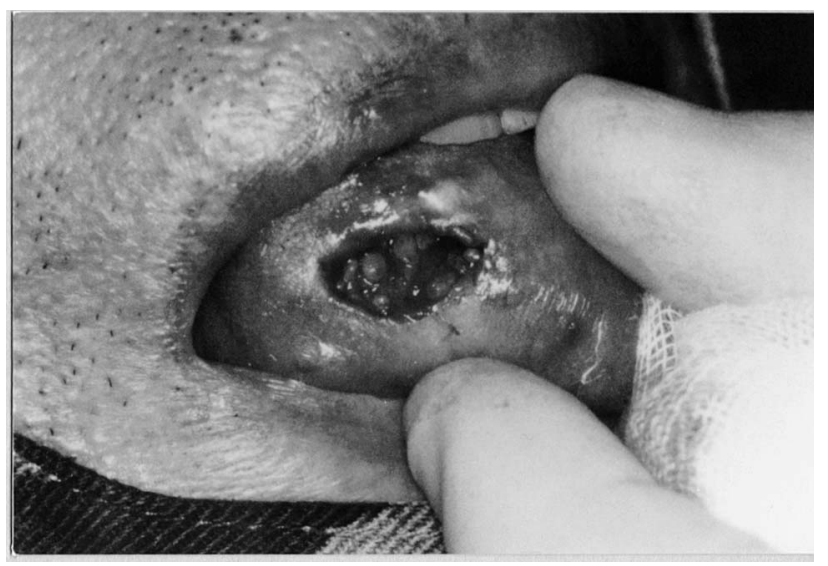

Fig. 2: The yellowish adipose tissues were seen just beneath the epithelium in the lateral border of the tongue.

radiological and histopathological findings. After the operation, re-examination of the whole body was carried out by dermatologist and physician. No fatty deposits were noted in other parts of the body, but a small hemangioma and cyst were detected in the liver.

\section{Discussion}

Benign symmetric lipomatosis (BSL) was first reported by Brodie in 1846 (6). Since then, approximately 200 cases of BSL have been reported in the literature (7). Some were reported as Madelung's disease $(8,9)$. BSL is characterized by diffuse symmetric deposits of adipose tissues in the neck. The neck masses achieve great size and become cosmetically deforming over several years, and the upper aerodigestive tract may be compressed in advanced disease, causing dyspnea and dysphagia. The fatty deposits are uncapsulated with multiple projections infiltrating and displacing the surrounding structures without destruction. Association with alcoholism has been reported in $60 \%$ to $90 \%$ of the patients (10). Hyperruricemia, gout, liver disease, polyneuropathy, diabetes, glucoseintolerance, peripheral insulin resistance, renal tubular acidosis, hypertension, hyperthyroidism, and

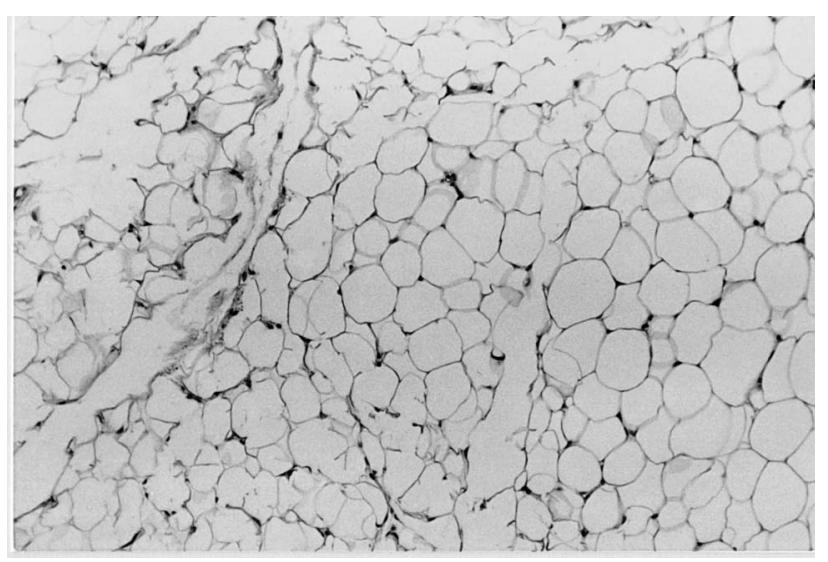

Fig. 3: The biopsy specimen showed adipose tissue consisting of mature lipocytes (H-E staining, $\times 100)$.

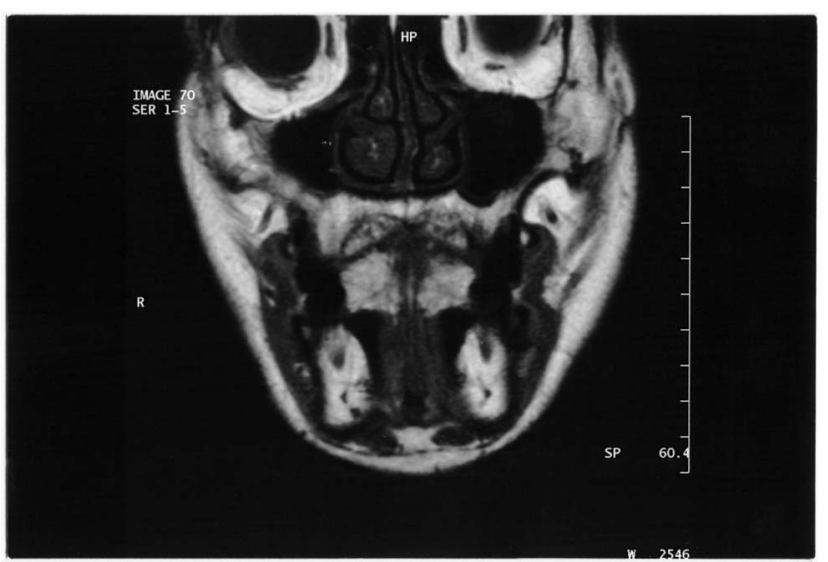

Fig. 4: MR image showed diffuse and irregular high intensity areas in the tongue ( $\mathrm{T} 1$ weighted image).

hyperlipidemia have been identified in patients with BSL (10).

On the other hand, symmetric lipomatosis of the tongue (SLT) is an extremly rare disease. Recently, CalvoGarcia et al. (5) reported a case of SLT and reviewed the literature (Table 1). According to Calvo-Garcia et al., in 6 cases of SLT, all patients were male and the mean age was 67 years (61-71 years). Four of the patients were Japanese and none of the 6 cases had the typical features of BSL: deposition of fat in the neck, shoulder and upper trunk. Only one Japanese patient was an alcoholic (3). The present case showed clinical features similar to those patients previously reported.

Histopathological findings of BSL and SLT were essentially the same: multiple site of involvement, invasiveness and absence of encapsulation of the adipose tissues. None of the patients with SLT showed the typical features of BSL, and lingual lipomatosis has not been reported in patients with BSL (5). Therefore, there has been some confusion on the etiology. Ogawa et al. (2) suggested that BSL and SLT are the same entity, but Katou et al. (3) and Calvo-Garcia et al. (5) suggested that they are different. Regarding the etiology of BSL, Pollock et al. 


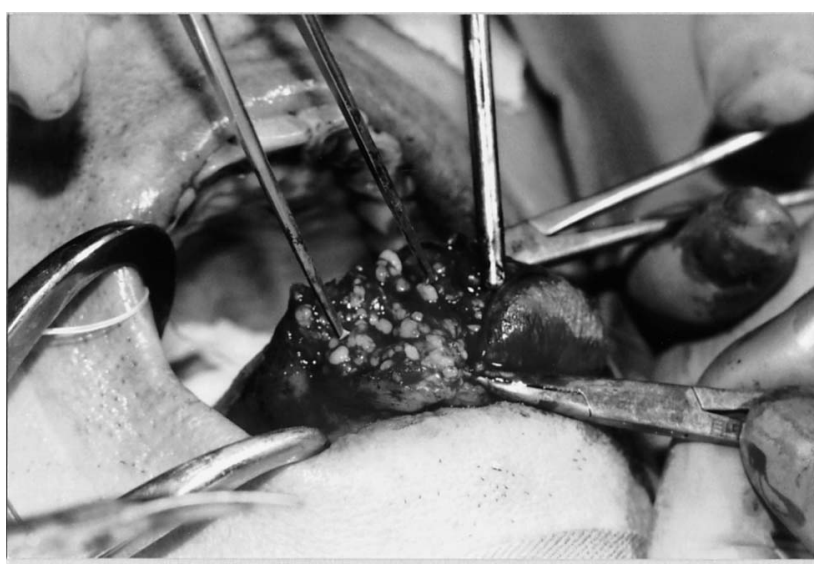

Fig. 5: The adipose tissues infiltrated into the lingual muscles, and capsule formation was not found.

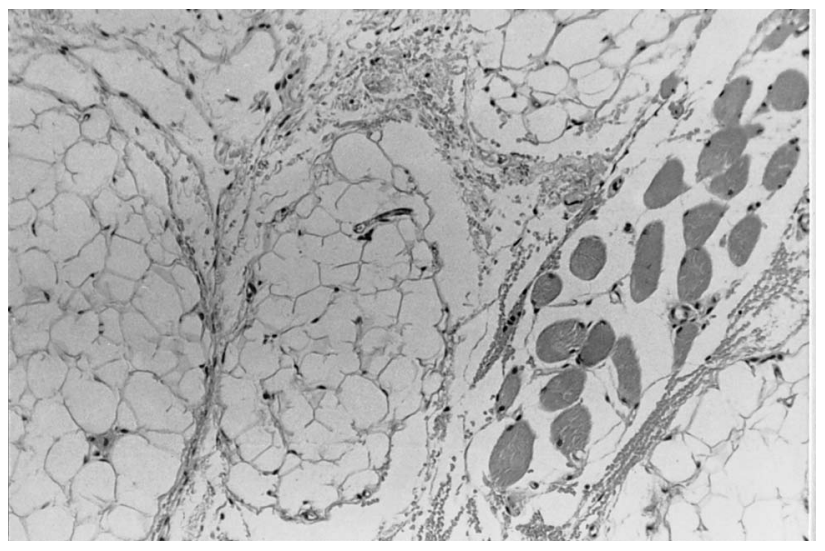

Fig. 6: The adipose tissues were interspersed with the muscle fibers $(\mathrm{H}-\mathrm{E}$ staining, $\times 100)$.

Table 1: Summary of reported cases of SLT (modified from Calvo-Garcia et al. 1999)

\begin{tabular}{|c|c|c|c|c|c|c|c|c|}
\hline Author & Year & Gender & Age & Alcoholism & Dysarthria & Dysphagia & $\begin{array}{l}\text { Systemic } \\
\text { disease }\end{array}$ & Treatment \\
\hline Desmond & 1944 & Male & 67 & - & + & + & $\begin{array}{l}\cdot \text { Diabetes } \\
\cdot \text { Mental } \\
\text { disorder }\end{array}$ & Glossectomy \\
\hline Ogawa et al. & 1988 & Male & 67 & + & Not clear & Not clear & - Stroke & Glossectomy \\
\hline $\begin{array}{l}\text { Yoshimura } \\
\text { et al. }\end{array}$ & 1988 & Male & 71 & - & + & + & $\begin{array}{l}\cdot \text { Angina } \\
\cdot \text { Raeder } \\
\text { syndrome }\end{array}$ & Glossectomy \\
\hline $\begin{array}{l}\text { Katou et al. } \\
\text { (Case 1) }\end{array}$ & 1993 & Male & 61 & - & + & + & $\begin{array}{l}\text { - Gastric } \\
\text { cancer }\end{array}$ & Glossectomy \\
\hline $\begin{array}{l}\text { Katou et al. } \\
\text { (Case 2) }\end{array}$ & 1993 & Male & 71 & $\begin{array}{l}\text { Mild } \\
\text { drinking }\end{array}$ & - & - & $\begin{array}{l}\cdot \text { Hyper } \\
\text {-tension }\end{array}$ & Glossectomy \\
\hline $\begin{array}{l}\text { Calvo-Garcia } \\
\text { et al. }\end{array}$ & 1999 & Male & 67 & - & \pm & - & - & Glossectomy \\
\hline Jinbu et al. & 2003 & Male & 72 & - & - & - & - Diabetes & Glossectomy \\
\hline
\end{tabular}

(11) suggested an abnormality in the amount and/or function of the Gs-protein, or in the catalytic unit of adenylate cyclase found in adipocyte membranes. Recently, Berkovic et al. (12) concluded that BSL is a manifestation of brown fat mitochondrial dysfunction. Although further analysis of more cases of SLT and BSL are needed, SLT may not be a neoplastic lesion but a fatty metabolic dysfunction. On the treatment of SLT, all cases have been managed by glossectomy (Table 1). As the adipose tissues infiltrate deep into the lingual muscles, complete resection is impossible. As the possibility of regrowth of the adipose tissues is undeniable and malignant transformation of SLT to myxoid liposarcoma occurred in one case, (13), long term follow-up is important. 


\section{References}

1. Desmond AD. A case of lipomatosis of the tongue. Br J Surg 1944; 35: 210.

2. Ogawa A, Nakamura $H$ and Takahashi H. Benign symmetric lipomatosis of the tongue: Report of a case. J Oral Maxillofac Surg 1988; 46: 502-4

3. Katou F, Shirai N, Motegi K, et al. Symmetric lipomatosis of the tongue presenting as macroglossia: Report of two cases. J Craniomaxillofac Surg 1993; 21: 298-301.

4. Yoshimura Y, Miyakawa A, Odani M, et al. A case of macroglossia caused by benign symmetric lipomatosis. Jpn J Oral Maxillofac Surg 1988; 34: 1061-5.

5. Calvo-Garcia N, Prieto-Prado M, Alonso-Orcajo N, et al. Symmetric lipomatosis of the tongue: Report of a case and review of the literature. Oral Surg Oral Med Oral Pathol Oral Radiol Endod 1999; 87: 610-2.

6. Brodie BC. Clinical Lectures on Surgery Delivered at St.George's Hospital. Lea \& Blanchard, Philadelphia. 1846; 201.

7. Shugar MA and Gavron JP. Benign symmetric lipomatosis (Madelung's disease). Otolaryngol Head Neck Surg 1985; 93 : 109-12.

8. Plotnicov NA, Babayev TA, Lamberg MA, et al. Madelung's disease (benign symmetric lipomatosis) . Oral Surg Oral Med Oral Pathol 1988; 66: 171-5.

9. Parmar SC and Blackburn C. Madelung's disease: An uncommon disorder of unknown aetiology? Br J Oral Maxillofac Surg 1996; 34: 467-70.

10. Kohan D, Millar PJ, Rothstein SG, et al. Madelung's disease: Case reports and literature review. Otolaryngol Head Neck Surg 1993; 108: 156-9.

11. Pallock M, Nicholoson GI, Nukada H, et al. Neuropathy in multiple symmetric lipomatosis. Madelung's disease. Brain 1988; 111: 1157-71.

12. Berkovic SF, Andermann F, Shoubrige EA, et al. Mitochondrial dysfunction in multiple symmetric lipomatosis. Ann Neurol 1991; 29: 566-9.

13. Tizian C, Berger A and Vykoupil KF. Malignant degeneration in Madelung's disease (benign lipomatosis of the neck): Case report. Br J Plast Surg 1983; 36: 187-9.

(Accepted for publication December 20, 2003) 